Article

\title{
Theranostic Liposome-Nanoparticle Hybrids for Drug Delivery and Bioimaging
}

\author{
Muharrem Seleci, Didem Ag Seleci, Thomas Scheper and Frank Stahl * \\ Institute of Technical Chemistry, Leibniz University of Hanover, Callinstr. 5, 30167 Hanover, Germany; \\ muharremseleci@hotmail.com (M.S.); didemag@hotmail.com (D.A.S.); scheper@iftc.uni-hannover.de (T.S.) \\ * Correspondence: stahl@iftc.uni-hannover.de; Tel.: +49-511-762-2968
}

Received: 2 June 2017; Accepted: 26 June 2017; Published: 2 July 2017

\begin{abstract}
Advanced theranostic nanomedicine is a multifunctional approach which combines the diagnosis and effective therapy of diseased tissues. Here, we investigated the preparation, characterization and in vitro evaluation of theranostic liposomes. As is known, liposome-quantum $\operatorname{dot}(\mathrm{L}-\mathrm{QD})$ hybrid vesicles are promising nanoconstructs for cell imaging and liposomal-topotecan (L-TPT) enhances the efficiency of TPT by providing protection against systemic clearance and allowing extended time for it to accumulate in tumors. In the present study, hydrophobic CdSe/ZnS QD and TPT were located in the bilayer membrane and inner core of liposomes, respectively. Dynamic light scattering (DLS), zeta potential ( $\zeta$ ) measurements and fluorescence/absorption spectroscopy were performed to determine the vesicle size, charge and spectroscopic properties of the liposomes. Moreover, drug release was studied under neutral and acidic $\mathrm{pH}$ conditions. Fluorescence microscopy and flow cytometry analysis were used to examine the cellular uptake and intracellular distribution of the TPT-loaded L-QD formulation. 3-(4,5-Dimethylthiazol-2-yl)-2,5-diphenyltetrazolium bromide (MTT) assay was utilized to investigate the in vitro cytotoxicity of the formulations on HeLa cells. According to the results, the TPT-loaded L-QD hybrid has adequate physicochemical properties and is a promising multifunctional delivery vehicle which is capable of a simultaneous co-delivery of therapeutic and diagnostic agents.
\end{abstract}

Keywords: theranostic liposomes; quantum dots; bioimaging; drug delivery

\section{Introduction}

Nanomedicine is an innovative field with enormous potential for treatment by a combination of smart nanoparticles with small molecules carrying a wide range of functions [1]. Quantum dots (QDs) are one of the promising nanoparticles with excellent fluorescence properties, including broad absorption spectra, narrow emission spectra, high quantum yields, resistance to photobleaching, and high photochemical stability [2-4]. Due to these characteristics, they have been explored as fluorescent probes for biomedical applications and are useful in particular for in vivo cell labeling and imaging [5-8].

Most QDs are typically produced in organic solvents, making them unsuitable for direct use in biomedical and clinical applications. To overcome this limitation, different surface coatings have been applied to increase the hydrophilicity of QDs $[9,10]$. However, surface modifications often lead to decreases in the QDs' fluorescence intensity and photostability. In an alternative approach, organic QDs are inserted into lipid bilayers to enhance their hydrophilicity, stability and biocompatibility [11-14].

Liposomes are self-assembled, spherical lipid-bilayer vesicles that are the most clinically established nanometer-scale systems [15]. They have the capacity to entrap both lipophilic and hydrophobic compounds in a lipid membrane and aqueous core, respectively. Thus, the stability, biocompatibility and solubility of the payloads could be enhanced with the use of several loading strategies. 
Liposome-QD (L-QD) hybrid vesicles have shown a great potential for theranostic applications [16]. Tian et al. studied the loading of doxorubicin (DOX) into L-QD hybrid vesicles by the $\mathrm{pH}$-gradient technique; they characterized these DOX-loaded vesicles using dynamic light scattering (DLS) and monitored DOX release [17]. Furthermore, Muthu et al. synthesized folic acid-conjugated theranostic liposomes for the targeted co-delivery of quantum dots and docetaxel [12]. In another study, apomorphine and QDs were integrated into multifunctional liposomes for brain targeting and bioimaging and the results showed that these liposomes can be accumulated to a large extent in the brain [18].

Topotecan (TPT) is a hydrophilic analog of camptothecin. It is a cell-cycle-specific drug and well established for the treatment of several cancers, including ovarian, small-cell lung and cervical cancer $[19,20]$. However, TPT is unstable in physiological conditions and undergoes a pH-dependent rapid and reversible hydrolysis from a closed lactone ring to the inactive carboxylated form. This causes the loss of the antitumor activity of the drug. To protect TPT from the hydrolysis, liposome has been used for encapsulation [21]. Liposomal encapsulation of TPT enhances its efficacy by protecting it from systemic clearance, allowing greater uptake and extended tissue exposure in solid tumors [22].

In the present study, the aim was to develop multifunctional theranostic liposomes which contain both the model drug TPT and QDs for cell therapy and imaging. For this purpose, L-QD hybrids were synthesized by the incorporation of hydrophobic QD within the lipid bilayer. The biocompatibility of the QDs was increased, retaining its fluorescence characteristics. The $\mathrm{pH}$-gradient technique was used to encapsulate TPT in the aqueous core of the liposome. Thus, TPT therapeutic activity and QD optical properties could be successfully integrated into one nanocarrier.

\section{Results and Discussion}

\subsection{Synthesis and Characterization of TPT-Loaded Liposomal Formulations}

The proportion of the lipids, distearoylphosphatidylcholine (DSPC) and cholesterol, was chosen to be 7:3. DSPC was selected as the bulk phospholipid component instead of egg phosphatidylcholine (EPC) or dimyristoylphosphatidylcholine (DMPC) to increase membrane rigidity, which can also increase drug retention in liposomes [23,24]. The influence of cholesterol on the stability of the liposomes has been intensively investigated, which has revealed that cholesterol in sufficient quantity $(\leq 30 \%)$ reduces the leakage of loaded materials from liposome by increasing their stability and decreasing their permeability $[25,26]$. Furthermore, cholesterol could enhance the hydrophobicity of the membrane [27]. Among various synthesis methods, the thin lipid layer hydration method is the most widely-used and simple method for the preparation of the liposomes. $\mathrm{pH}$-gradient technique, which is based on $\mathrm{pH}$ gradients as a driving force for the accumulation of the weakly-basic molecules into acidic vesicles, was used to encapsulate TPT into the aqueous core of the liposomes, protecting its active lactone form until released. The fluorescence spectra of the free drug and liposomal formulations were measured and indicated that both QD and TPT peaks could be simultaneously observed in the spectrum (Figure 1). This indicates the coexistence of both molecules in the vesicle. Fluorescence localizations of the molecules are also photographed in a large liposome (Figure S1). 


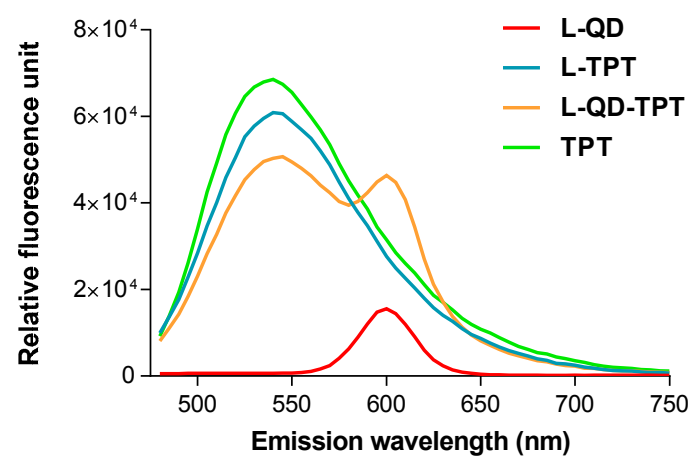

Figure 1. The fluorescence spectra of liposome-quantum dot (L-QD) (red), liposome-topotecan (L-TPT) (turquoise), L-QD-TPT (orange) and free TPT (green). The excitation wavelength was set at $450 \mathrm{~nm}$.

The physicochemical properties of nanoparticles are an important factor in protein interactions [28]. It has been reported that nanoparticles having a size less than $150 \mathrm{~nm}$ are more suitable for permeating through the disorganized and leaky microvasculature of the tumor cells. Besides, their more pronounced surface curvature may also reduce the clearance of the particles as a result of reduced interaction with the surface receptors on macrophages [29,30]. In this regard, to determine hydrodynamic diameters and the surface charge of the liposomes, DLS and $\zeta$-potential analysis were carried out (Table 1). The average size of the plain liposomes was measured as $\sim 132 \mathrm{~nm}$. After QD entrapment in the lipid bilayer, a $\sim 6 \mathrm{~nm}$ increase in liposome size was detected. This could be associated with the successful encapsulation of the molecules. TPT encapsulation into L-QD did not have an effect on the size (Figure S2). Besides, liposomes were tested for stability upon storage. Over 2 months, no significant differences in size distribution, $\zeta$-potential as well as PDI occurred at $4{ }^{\circ} \mathrm{C}$.

The higher surface charge of nanoparticles affects the amount of protein adsorption as well as protein corona composition on the surface [31,32]. Studies have signified that liposomes which contain highly charged lipids are more susceptible to rapid clearance by the reticuloendothelial system (RES). However, neutral and slightly negatively charged nanoparticles have a longer circulation lifetime and less accumulation in RES [33-35]. In the present study, $\zeta$-potential measurements revealed that the surface potential of the liposomes was slightly negative and encapsulations did not show significant alteration in surface charge. TPT encapsulation efficiency was calculated around $40 \%$. QD incorporation into the lipid bilayer of liposomes affected just $\sim 4 \%$ of TPT loading through the lipid membrane. Besides, the obtained polydispersity index values were lower than 0.1 , confirming the homogeneity of the liposomes (Table 1). Accordingly, the hybrid liposomes have better physicochemical properties.

Table 1. Physicochemical properties and EE\% of the liposomes.

\begin{tabular}{ccccc}
\hline Samples & Size $(\mathbf{n m})$ & PDI & $\zeta$-Potential $(\mathbf{m V})$ & EE (\%) \\
\hline L & $131.8 \pm 0.8$ & 0.082 & $-13.6 \pm 1.6$ & - \\
L-QD & $138.1 \pm 0.7$ & 0.014 & $-7.8 \pm 0.1$ & - \\
L-TPT & $134.1 \pm 1.2$ & 0.073 & $-10.6 \pm 0.1$ & 43.8 \\
L-QD-TPT & $137.1 \pm 1.7$ & 0.069 & $-6.0 \pm 0.1$ & 39.5 \\
\hline
\end{tabular}

The data are presented as the mean \pm standard deviation $(n=3)$. PDI: Polydispersity index; $\zeta$-potential: zeta potential; EE: Encapsulation efficiency \%.

\subsection{In Vitro Drug Release}

The in vitro drug release profile of L-QD-TPT was investigated by the dialysis method, which is one of the most common methods for the determination of drug release from the nanoparticles. The analysis was carried out in simulated conditions of normal human tissue $(\mathrm{pH} 7.4)$ and a tumor 
microenvironment ( $\mathrm{pH}$ 5.6) at $37^{\circ} \mathrm{C}$. The acidic environment led to an increased TPT release as compared to neutral conditions (Figure 2). The drug was released with an initial modest burst in the first $4 \mathrm{~h}$ followed by slower rates of release up to $32 \mathrm{~h}$. After $32 \mathrm{~h}$, the release rates of TPT were $39 \%$ at $\mathrm{pH} 7.4$ and $45 \%$ at $\mathrm{pH}$ 5.6. The higher release rate at an acidic $\mathrm{pH}$ can be ascribed to the solubility of the TPT, which increased with decreasing $\mathrm{pH}$ as a result of protonation [36].

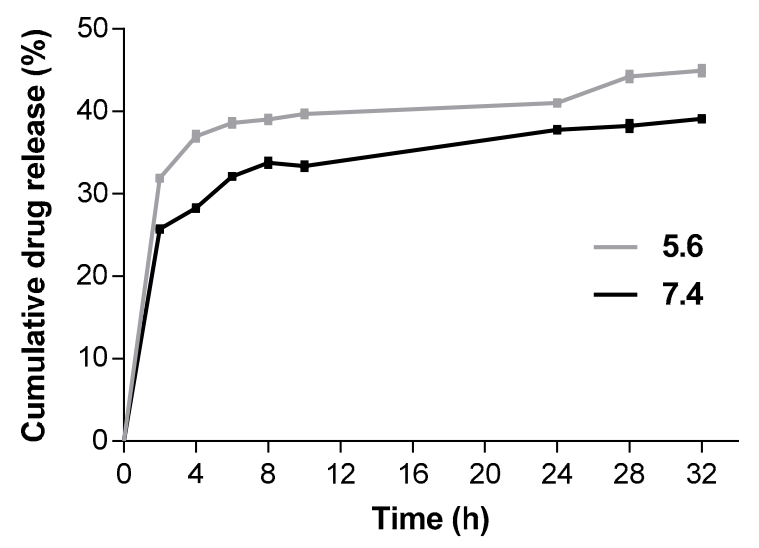

Figure 2. Cumulative drug release profile for L-QD-TPT at mild acidic ( $\mathrm{pH} 5.6)$ and neutral conditions (pH 7.4). Data are presented as mean $\pm \mathrm{SD}(n=3)$.

\subsection{Cellular Uptake and Internalization}

Cellular uptake of liposomal formulations was examined via flow cytometry. Cells were treated with the samples for $2 \mathrm{~h}$ and analyzed using a flow cytometer (BD FACSAria Fusion, Becton, Dickinson and Company, Franklin Lakes, NJ, USA). A UV excitation laser (at $400 \mathrm{~nm}$ ) was used for all measurements. Higher fluorescence signals (geometric mean values) were obtained from cells treated with the samples compared with untreated control cells. As is clear from Figure 3a, intracellular TPT level for L-TPT (3839 a.u.) and L-QD-TPT (4007 a.u.) in HeLa cells was higher than that of free TPT (2472 a.u.). This difference can be explained by their different uptake mechanisms. Free TPT, a small molecule, is mainly taken into the cells via passive diffusion, whereas liposomes enter the cells through endocytosis $[37,38]$. Besides, QD-loaded liposomes were also successfully taken up by the cells (Figure 3b).

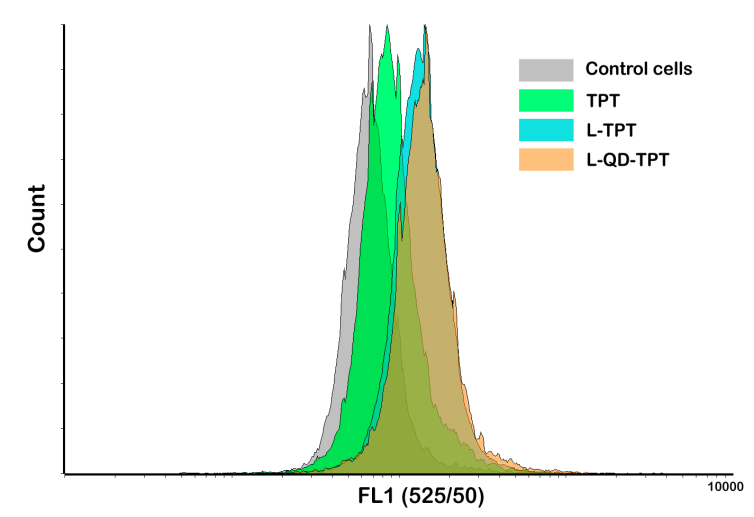

(a)

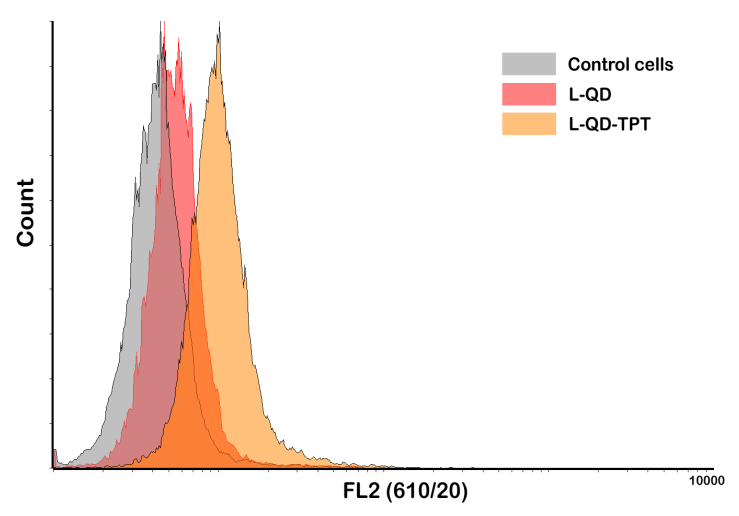

(b)

Figure 3. Cellular uptakes of the conjugates were determined in HeLa cells by flow cytometry. TPT, L-TPT, L-QD-TPT (a) (excitation at $400 \mathrm{~nm}$, emission filter FL1 (525/50 nm)); L-QD and L-QD-TPT (b) (excitation at $400 \mathrm{~nm}$, emission filter FL2 (610/20 nm)). 
Fluorescence microscopy was used to observe the cellular internalization of the liposomes. The images were acquired with separate filter sets. In cells treated with L-QD-TPT, the selected fluorescent model drug TPT, which is a topoisomerase-I inhibitor, localized, unsurprisingly, in cell nuclei to exert its toxicity $[39,40]$. The fluorescence from green TPT and blue $4^{\prime}, 6$-diamidino-2-phenylindole (DAPI) (nuclear stain) matched well (Figure 4a,c). Besides, the Figure $4 \mathrm{~b}$ and merged picture (Figure 4d) showed punctate red spots, indicating that QDs had escaped from the endosomes and co-localized in the cytoplasm and partially in the nucleus. The results are compatible with the outcomes of flow cytometry analysis as well as with the literature [12]. Dubertret et al. reported the encapsulation of CdSe/ZnS QDs into phospholipid block-copolymer micelles for in vitro and in vivo imaging. The QD-micelles injected into individual cells of an early embryo and the internalized QDs were localized to both the cytosol and nuclear envelope. Besides, QD cytotoxicity was dose dependent [41].

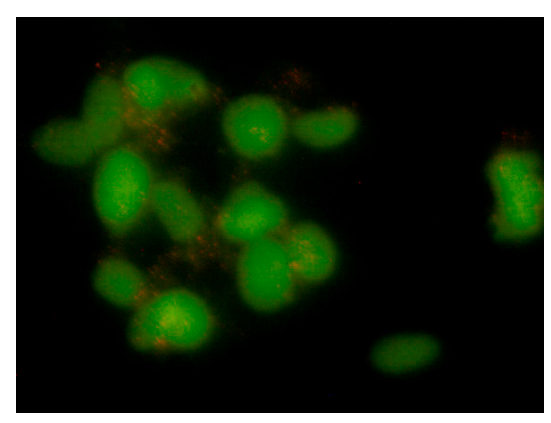

(a)

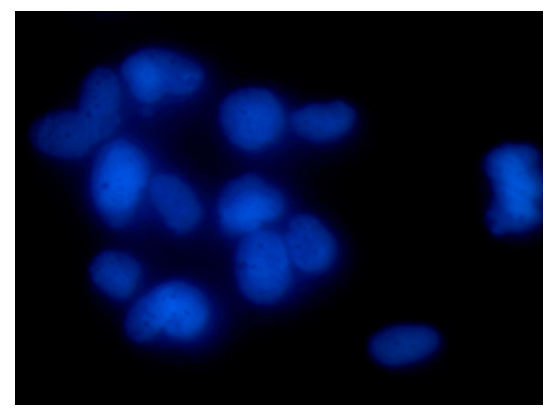

(c)

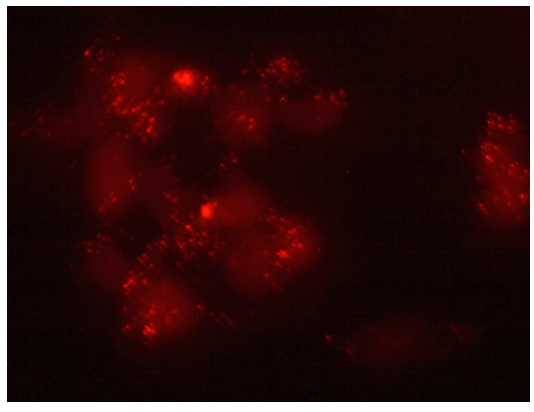

(b)

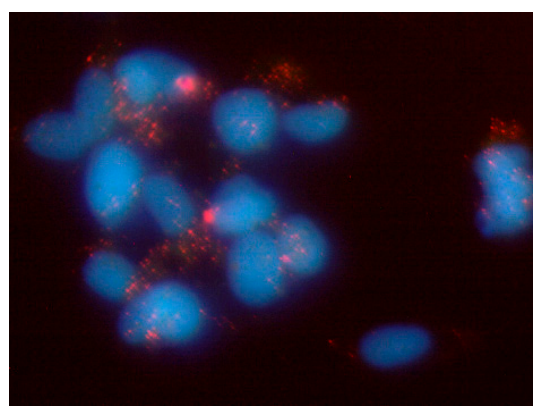

(d)

Figure 4. Fluorescence microscopy of HeLa cells after incubation with L-QD-TPT. Liposomes released the payload into the cell (a: TPT; b: QD). Nuclei were stained with $4^{\prime}$,6-diamidino-2-phenylindole (DAPI) (c). The obtained images were merged into the same picture (d). All pictures are in $40 \times$ magnification.

\subsection{Cytotoxicity}

The cytotoxicity of the liposomal formulations and free TPT on HeLa cells were determined by 3-(4,5-Dimethylthiazol-2-yl)-2,5-diphenyltetrazolium bromide (MTT) assay. Only viable cells with active metabolism are able to convert MTT into purple-colored formazan; the quantity of the formazan is measured by recording the changes in absorbance at $570 \mathrm{~nm}$ to $630 \mathrm{~nm}$ as the reference wavelength. According to the results, L-QD had no toxic effect due to effective shielding of QD by lipid bilayer from the surroundings. Similar results were also obtained by Chinnathambi and his colleagues. They used phosphoethanolamine(polyethylene glycol)-based phospholipid micelles to encapsulate CdSe/ZnS QDs and QD-micelles showed almost no toxicity in the concentration range of $0-25 \mu \mathrm{g} / \mathrm{mL}$ in HeLa and A549 cell lines exposed for up to $24 \mathrm{~h}$ [42], whereas L-TPT and L-QD-TPT showed obvious toxic effects on HeLa cells compared to free TPT for $24 \mathrm{~h}(p<0.05$, Figure 5). This is attributed to the facts that L-TPT and L-QD-TPT were taken up into the cells more efficiently (Figure 3) and that the TPT concentration released from liposomes is somewhat higher compared to that of free TPT. Hao et al. also 
found similar results regarding the enhancement of the antiproliferation ability of TPT with liposomal encapsulation [43].

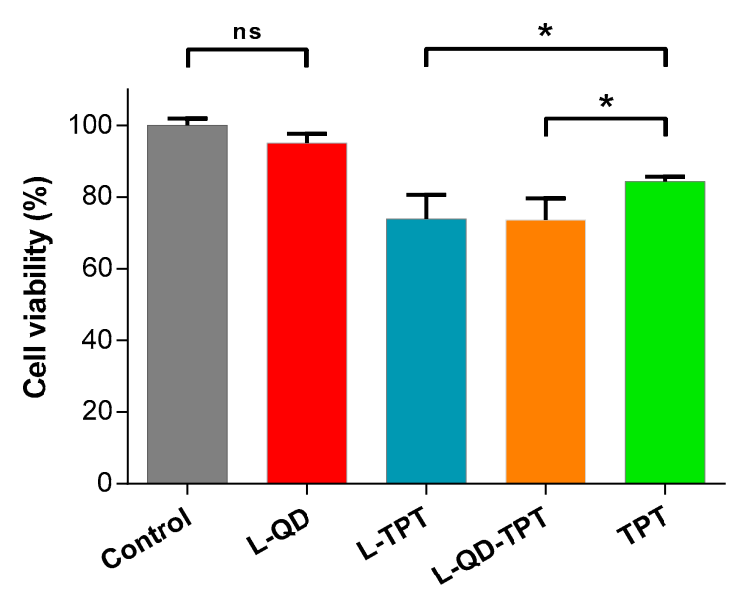

Figure 5. Cytotoxicity of the liposomal formulations and free TPT on HeLa cells. Cells were incubated with, L-QD, L-TPT, L-QD-TPT and free TPT (equivalent concentration of loaded TPT, $2.0 \mu \mathrm{g} / \mathrm{mL}$ ) for 24 h. 3-(4,5-Dimethylthiazol-2-yl)-2,5-diphenyltetrazolium bromide (MTT) assay was applied. Error bars represent the standard deviation from the mean $(n=3)$. Data were analyzed using $t$-test, and ${ }^{*} p<0.05$ was considered significant. ns: not significant.

\section{Materials and Methods}

\subsection{Materials}

The 3-(4,5-Dimethylthiazol-2-yl)-2,5-diphenyltetrazolium bromide (MTT), 4,6-diamino-2phenylindol (DAPI), Dulbecco's modified eagle medium (DMEM) and cholesterol were ordered from Sigma Aldrich (Munich, Germany). CdSe/ZnS core/shell hydrophobic quantum dots (QDs) with an overall diameter of $\sim 5 \mathrm{~nm}$ were obtained from PlasmaChem GmbH (Berlin, Germany). Topotecan and 1,2-distearoyl-sn-glycero-3-PC (DSPC) were purchased from Cayman Chemical (Ann Arbor, MI, USA).

\subsection{Synthesis of $L-Q D$ Hybrids}

L-QD hybrids were synthesized by the thin film hydration method [44]. Briefly, DSPC:Cholesterol (7:3 molar ratio) and $30 \mu \mathrm{g} / \mathrm{mL}$ CdSe $/ \mathrm{ZnS}$ QD $\left(\lambda_{\mathrm{em}}=600 \mathrm{~nm}\right)$ solutions in chloroform were added into a round bottom flask. The mixture was placed in an evaporator to obtain a thin QD-containing lipid film and exposed to $\mathrm{N}_{2}$ gas for just a few minutes to remove the residual of organic solvents. The dried film was hydrated with $250 \mathrm{mM}$ ammonium sulphate $(\mathrm{pH} 6.5)$ at $60{ }^{\circ} \mathrm{C}$, which is above the gel-liquid melting transition temperature (Tm) of all lipids. Small unilamellar vesicles (SUVs) were prepared starting from multilamellar vesicles (MLVs) by using sonication and extruding through $0.4 \mu \mathrm{m}$ and $0.1 \mu \mathrm{m}$ pore size polycarbonate membranes in mini-extruder set (Avanti Polar Lipids, Alabaster, AL, USA). Afterward, liposomes were centrifuged at 11,000 rpm for $15 \mathrm{~min}$ to remove the excess non-incorporated quantum dots [45].

\subsection{Encapsulation of Model Drug TPT}

L-QD hybrids were loaded actively with TPT using the pH-gradient technique [46]. The obtained lipid-QD dried thin film was hydrated with $250 \mathrm{mM}$ ammonium sulphate $\left(\mathrm{pH}\right.$ 6.5) at $60{ }^{\circ} \mathrm{C}$. After sonication, dialyzed against $10 \mathrm{mM}$ HEPES buffered saline (HBS, pH 7.5) to adjust the exterior $\mathrm{pH}$ value of the liposomes as in physiological conditions. The suspension was then mixed with $0.1 \mathrm{mM}$ TPT solution (in $0.9 \% \mathrm{NaCl}$ ) followed by $1 \mathrm{~h}$ incubation in a $60^{\circ} \mathrm{C}$ water bath. L-QD-TPT was 
extruded through $0.4 \mu \mathrm{m}$ and $0.1 \mu \mathrm{m}$ polycarbonate membranes, respectively. Finally, liposomes were centrifuged at 11,000 rpm for $15 \mathrm{~min}$ to remove the excess non-incorporated molecules.

\subsection{Encapsulation Efficiency}

The percent of encapsulation efficiency (EE\%) of TPT was calculated according to the following Equation (1):

$$
E \%_{\mathrm{TPT}}=\left(W_{\mathrm{en}} / W_{\text {total }}\right) \times 100 \%
$$

where $W_{\text {en }}$ is the analyzed weight of the drug encapsulated in liposome and $W_{\text {total }}$ is the initial amount of the drug [47]. It was determined after lysis of the liposomes by diluting purified liposomes in acidic methanol ( $1 \%$ trifluoroacetic acid in methanol). Calibration curves were established with known concentrations of free TPT by fluorescence emission measurements at $530 \mathrm{~nm}$ using a fluorospectrometer (NanoDrop 3300, Thermo Fisher Scientific Inc., Waltham, MA, USA).

\subsection{Characterization}

The fluorescence spectra of the free drug and liposomal formulations were measured using a spectrofluorometer. The localizations of QD and TPT in a large liposome were photographed using an Olympus BX41 fluorescence microscope (Shinjuku, Tokyo, Japan) equipped with an Olympus SC30 camera and processed by Image J software [48].

The particle size distribution and zeta potential ( $\zeta$ ) of the liposomes were determined by Zetasizer Nano-ZS (Malvern Instruments, Malvern, UK). The polydispersity index (PDI) was reported as a measure of the width of size distribution. The samples were diluted at the ratio of 1:100 $(v / v)$ with $\mathrm{ddH}_{2} \mathrm{O}$ and equilibrated for $3 \mathrm{~min}$ before the measurements. Measurements were taken three times at room temperature. To test their stability, liposomal formulations were stored at $4{ }^{\circ} \mathrm{C}$ in the dark. After 2 months, their size distribution, $\zeta$-potential and PDI were analyzed.

\subsection{In Vitro Drug Release}

The dialysis technique was used for drug release experiments. L-QD-TPT was prepared and transferred into a pre-washed dialysis tubing (Slide-A-Lyzer MINI Dialysis Devices, 10K MWCO, Thermo Fisher Scientific Inc., Waltham, MA, USA). The tubing was immersed in $10 \mathrm{~mL}$ of the Phosphate buffered saline (PBS) buffer ( $\mathrm{pH} 5.6$ and 7.4), placed in an incubator at $37^{\circ} \mathrm{C}$ and stirred at $100 \mathrm{rpm}$. At specific time intervals, $0.5 \mathrm{~mL}$ samples were removed from the release medium and replaced with the same volume of fresh buffer. The amount of released TPT was calculated according to the calibration curves. They were established with a known concentration of free TPT by fluorescence emission measurements at $530 \mathrm{~nm}$ using a spectrofluorometer.

\subsection{Cell Culture}

Human cervical cancer cell (HeLa cell) line was provided from the German Collection of Microorganisms and Cell Cultures (DSMZ) (Braunschweig, Germany). Cells were grown in DMEM containing $10 \%$ fetal calf serum (FCS) and $1.0 \%$ penicillin/streptomycin (P/S). HeLa cells were cultivated in this medium and incubated with samples and reagents at $37{ }^{\circ} \mathrm{C}$ in a humidified environment with $5.0 \% \mathrm{CO}_{2}$.

\subsection{Cytotoxicity}

The MTT (3-(4,5-dimethylthiazol-2-yl)-2,5-diphenyltetrazolium bromide) assays were used to determine the cytotoxicity of the liposomal formulations. Cells $\left(8 \times 10^{3}\right)$ were seeded out in 96 -well tissue plates (Sarstedt, Newton, MA, USA) in a volume of $200 \mu \mathrm{L}$ and cultivated for three days. After this cultivation period, cells were washed once with PBS and treated with L-QD, L-TPT, L-QD-TPT and free TPT for $24 \mathrm{~h}$. The equivalent concentration of free TPT was used in liposomal formulations. The samples were then removed and the cells were incubated in $110 \mu \mathrm{L} /$ well 10\% MTT 
solution $(5.0 \mathrm{mg} / \mathrm{mL}$ in PBS) in the medium for $4 \mathrm{~h}$. During this incubation time, formazan complex was produced by the cells. A $100 \mu \mathrm{L}$ SDS solution $(1.0 \mathrm{~g}$ SDS in $10 \mathrm{~mL} 0.01 \mathrm{M} \mathrm{HCl})$ was added to each well to release the purple-colored salt from the cells. After $24 \mathrm{~h}$ of incubation, UV-Vis absorption was measured at $570 \mathrm{~nm}$ to $630 \mathrm{~nm}$ as the reference wavelength using a microplate reader (Epoch BioTek, Winooski, VT, USA).

\subsection{Cellular Uptake and Internalization}

The cellular uptake of TPT and liposomal formulations by HeLa cells was examined through flow cytometry. Cells $\left(5 \times 10^{5}\right)$ were collected and incubated with the samples for $2 \mathrm{~h}$, followed by washing two times with PBS. Just before the analysis, cells were resuspended in $500 \mu \mathrm{L}$ of PBS and then analyzed in a BD FACSAria Fusion flow cytometer (Becton, Dickinson and Company, Franklin Lakes, NJ, USA). At least 20,000 gated events were observed in total and living cells were gated in a dot plot of forward versus side scatter signals. The dot plot and histogram data were analyzed by Flowing Software 2 [49].

Cellular internalization of L-QD-TPT was determined via fluorescence microscopy studies. HeLa cells were cultivated for 2 days on the chamber slides (8-well $\mu$ slides purchased from ibidi GmbH, Munich, Germany) in a volume of $200 \mu \mathrm{L}$ of the medium. Samples were diluted with the medium and then added to the cells. The cells were incubated for $4 \mathrm{~h}$ at $37^{\circ} \mathrm{C}$ and washed twice in PBS. Afterwards, $100 \mu \mathrm{L}$ DAPI solution $(1.0 \mathrm{mg} / \mathrm{mL})$ was added to the cells, which were then incubated for $15 \mathrm{~min}$. Cells were washed with PBS once following DAPI staining. Images were taken using an Olympus BX41 fluorescence microscope equipped with an Olympus SC30 camera and processed by Image J software.

\subsection{Statistical Analysis}

Statistical data analysis was performed using the Student's $t$-test. The difference between two groups was considered to be significant when the $p$-value was less than 0.05 .

\section{Conclusions}

The theranostic liposomes, with a mean size of about $135 \mathrm{~nm}$, were developed for the co-delivery of imaging and therapeutic agents. Both hydrophobic QD and hydrophilic TPT were encapsulated into liposomes by thin film hydration and $\mathrm{pH}$-gradient methods, respectively. Thus, bioavailability of a poorly water-soluble molecule was enhanced and moreover, the therapeutic efficacy and stability of the drug were improved. The well-characterized liposomal TPT formulations showed significantly higher cellular uptake as well as higher cytotoxicity than free TPT. QD internalization into cells was achieved and enabled simultaneous imaging. This liposome-nanoparticle hybrid system might offer new opportunities for the development of novel co-delivery platforms.

Supplementary Materials: Supplementary materials can be found at www.mdpi.com/1422-0067/18/7/1415/s1.

Acknowledgments: Part of this work was founded by BioFabrication for NIFE. We wish to thank André Jochums for his help with flow cytometry analysis. Konrad Adenauer Foundation is acknowledged for the financial support to Didem Ag Seleci. The publication of this article was funded by the Open Access Fund of the Leibniz Universität Hannover.

Author Contributions: Muharrem Seleci designed and performed the experiments, analyzed data and wrote the paper; Didem Ag Seleci carried out the cytotoxicity and cellular uptake experiments; Thomas Scheper and Frank Stahl contributed writing the paper.

Conflicts of Interest: The authors declare no conflict of interest.

\section{References}

1. Seleci, M.; Ag Seleci, D.; Joncyzk, R.; Stahl, F.; Blume, C.; Scheper, T. Smart multifunctional nanoparticles in nanomedicine. BioNanoMaterials 2016, 17, 33-41. [CrossRef]

2. Bruchez, M.; Moronne, M.; Gin, P.; Weiss, S.; Alivisatos, A.P. Semiconductor nanocrystals as fluorescent biological labels. Science 1998, 281, 2013-2016. [CrossRef] [PubMed] 
3. Jaiswal, J.K.; Mattoussi, H.; Mauro, J.M.; Simon, S.M. Long-term multiple color imaging of live cells using quantum dot bioconjugates. Nat. Biotechnol. 2003, 21, 47-51. [CrossRef] [PubMed]

4. Resch-Genger, U.; Grabolle, M.; Cavaliere-Jaricot, S.; Nitschke, R.; Nann, T. Quantum dots versus organic dyes as fluorescent labels. Nat. Methods 2008, 5, 763-775. [CrossRef] [PubMed]

5. Rizvi, S.B.; Rouhi, S.; Taniguchi, S.; Yang, S.Y.; Green, M.; Keshtgar, M.; Seifalian, A.M. Near-infrared quantum dots for HER2 localization and imaging of cancer cells. Int. J. Nanomed. 2014, 9, 1323-1337.

6. Ag, D.; Bongartz, R.; Dogan, L.E.; Seleci, M.; Walter, J.-G.; Demirkol, D.O.; Stahl, F.; Ozcelik, S.; Timur, S.; Scheper, T. Biofunctional quantum dots as fluorescence probe for cell-specific targeting. Colloids Surf. B 2014, 114, 96-103. [CrossRef] [PubMed]

7. Gao, X.; Cui, Y.; Levenson, R.M.; Chung, L.W.K.; Nie, S. In vivo cancer targeting and imaging with semiconductor quantum dots. Nat. Biotechnol. 2004, 22, 969-976. [CrossRef] [PubMed]

8. Sounderya, N.; Zhang, Y. Use of core/shell structured nanoparticles for biomedical applications. Recent Pat. Biomed. Eng. 2008, 1, 34-42. [CrossRef]

9. Akin, M.; Bongartz, R.; Walter, J.G.; Demirkol, D.O.; Stahl, F.; Timur, S.; Scheper, T. PAMAM-functionalized water soluble quantum dots for cancer cell targeting. J. Mater. Chem. 2012, 22, 11529-11536. [CrossRef]

10. Smith, A.M.; Duan, H.; Rhyner, M.N.; Ruan, G.; Nie, S. A systematic examination of surface coatings on the optical and chemical properties of semiconductor quantum dots. Phys. Chem. Chem. Phys. 2006, 8, 3895-3903. [CrossRef] [PubMed]

11. Al Jamal, W.T.; Al Jamal, K.T.; Bomans, P.H.; Frederik, P.M.; Kostarelos, K. Functionalized Quantum dot liposome hybrids as multimodal nanoparticles for cancer. Small 2008, 4, 1406-1415. [CrossRef] [PubMed]

12. Muthu, M.S.; Kulkarni, S.A.; Raju, A.; Feng, S.-S. Theranostic liposomes of TPGS coating for targeted co-delivery of docetaxel and quantum dots. Biomaterials 2012, 33, 3494-3501. [CrossRef] [PubMed]

13. Gopalakrishnan, G.; Danelon, C.; Izewska, P.; Prummer, M.; Bolinger, P.Y.; Geissbahler, I.; Demurtas, D.; Dubochet, J.; Vogel, H. Multifunctional lipid/quantum dot hybrid nanocontainers for controlled targeting of live cells. Angew. Chem. Int. Ed. 2006, 45, 5478-5483. [CrossRef] [PubMed]

14. Yang, C.; Chen, W.; Bui, B.Q.; Xiang, G. Recent progress on the liposomes loaded with quantum dots. Rev. Nanosci. Nanotechnol. 2012, 1, 257-270. [CrossRef]

15. Riehemann, K.; Schneider, S.W.; Luger, T.A.; Godin, B.; Ferrari, M.; Fuchs, H. Nanomedicine-challenge and perspectives. Angew. Chem. Int. Ed. 2009, 48, 872-897. [CrossRef] [PubMed]

16. Muthu, M.S.; Leong, D.T.; Mei, L.; Feng, S.-S. Nanotheranostics-application and further development of nanomedicine strategies for advanced theranostics. Theranostics 2014, 4, 660-677. [CrossRef] [PubMed]

17. Tian, B.; Kostarelos, K. The engineering of doxorubicin-loaded liposome-quantum dot hybrids for cancer theranostics. Chin. Phys. B. 2014, 23, 087805. [CrossRef]

18. Wen, C.J.; Zhang, L.-W.; Al-Suwayeh, S.A.; Yen, T.-C.; Fang, J.-Y. Theranostic liposomes loaded with quantum dots and apomorphine for brain targeting and bioimaging. Int. J. Nanomed. 2012, 7, 1599-1611.

19. Grahn, A.Y.; Bankiewicz, K.S.; Dugich-Djordjevic, M.; Bringas, J.R.; Hadaczek, P.; Johnson, G.A.; Eastman, S.; Luz, M. Non-PEGylated liposomes for convection-enhanced delivery of topotecan and gadodiamide in malignant glioma: Initial experience. J. Neurooncol. 2009, 95, 185-197. [CrossRef] [PubMed]

20. Chen, Z.J.; Zhang, Z.; Xie, B.B.; Zhang, H.Y. Development and evaluation of topotecan loaded solid lipid nanoparticles: A study in cervical cancer cell lines. J. Photochem. Photobiol. B 2016, 165, 182-188. [CrossRef] [PubMed]

21. Hao, Y.L.; Deng, Y.-J.; Chen, Y.; Wang, X.M.; Zhong, H.-J.; Suo, X.-B. In vitro and in vivo studies of different liposomes containing topotecan. Arch. Pharm. Res. 2005, 28, 626-635. [CrossRef] [PubMed]

22. Tardi, P.; Choice, E.; Masin, D.; Redelmeier, T.; Bally, M.; Madden, T.D. Liposomal encapsulation of topotecan enhances anticancer efficacy in murine and human xenograft models. Cancer Res. 2000, 60, 3389-3393. [PubMed]

23. Mayer, L.D.; Tai, L.C.; Ko, D.S.; Masin, D.; Ginsberg, R.S.; Cullis, P.R.; Bally, M.B. Influence of vesicle size, lipid composition, and drug-to-lipid ratio on the biological activity of liposomal doxorubicin in mice. Cancer Res. 1989, 49, 5922-5930. [PubMed]

24. Lim, H.J.; Masin, D.; McIntosh, N.L.; Madden, T.D.; Bally, M.B. Role of drug release and liposome-mediated drug delivery in governing the therapeutic activity of liposomal mitoxantrone used to treat human A431 and LS180 solid tumors. J. Pharmacol. Exp. Ther. 2000, 292, 337-345. [PubMed] 
25. Semple, S.C.; Chonn, A.; Cullis, P.R. Influence of cholesterol on the association of plasma proteins with liposomes. Biochemistry 1996, 35, 2521-2525. [CrossRef] [PubMed]

26. Bozzuto, G.; Molinari, A. Liposomes as nanomedical devices. Int. J. Nanomed. 2015, 10, 975-999. [CrossRef] [PubMed]

27. Magarkar, A.; Dhawan, V.; Kallinteri, P.; Viitala, T.; Elmowafy, M.; Róg, T.; Bunker, A. Cholesterol level affects surface charge of lipid membranes in saline solution. Sci. Rep. 2014, 4, 5005. [CrossRef] [PubMed]

28. Rahman, M.; Laurent, S.; Tawil, N.; Yahia, L.H.; Mahmoudi, M. Nanoparticle and protein corona. In Protein-Nanoparticle Interactions; Springer: Berlin, Germany, 2013; pp. 21-44. ISBN 978-3-642-37554-5.

29. Farokhzad, O.C.; Jon, S.; Langer, R. A. Ptamers and cancer nanotechnology. In Nanotechnology for Cancer Therapy; Amiji, M.M., Ed.; CRC Press: Boca Raton, FL, USA, 2006; pp. 289-341. ISBN 978-0-8493-7194-3.

30. Brigger, I.; Dubernet, C.; Couvreur, P. Nanoparticles in cancer therapy and diagnosis. Adv. Drug Deliv. Rev 2002, 54, 631-651. [CrossRef]

31. Deng, Z.J.; Liang, M.; Toth, I.; Monteiro, M.; Minchin, R.F. Plasma protein binding of positively and negatively charged polymer-coated gold nanoparticles elicits different biological responses. Nanotoxicology 2013, 7, 314-322. [CrossRef] [PubMed]

32. Gessner, A.; Lieske, A.; Paulke, B.R.; Muller, R.H. Influence of surface charge density on protein adsorption on polymeric nanoparticles: Analysis by two-dimensional electrophoresis. Eur. J. Pharm. Biopharm. 2002, 54, 165-170. [CrossRef]

33. Blanco, E.; Shen, H.; Ferrari, M. Principles of nanoparticle design for overcoming biological barriers to drug delivery. Nat. Biotechnol. 2015, 33, 941-951. [CrossRef] [PubMed]

34. Levchenko, T.S.; Rammohan, R.; Lukyanov, A.N.; Whiteman, K.R.; Torchilin, V.P. Liposome clearance in mice: The effect of a separate and combined presence of surface charge and polymer coating. Int. J. Pharm. 2002, 240, 95-102. [CrossRef]

35. Zhao, W.; Zhuang, S.; Qi, X.-R. Comparative study of the in vitro and in vivo characteristics of cationic and neutral liposomes. Int. J. Nanomed. 2011, 6, 3087-3098.

36. Padhi, S.; Mirza, M.A.; Verma, D.; Khuroo, T.; Panda, A.K.; Talegaonkar, S.; Khar, R.K.; Iqbal, Z. Revisiting the nanoformulation design approach for effective delivery of topotecan in its stable form: An appraisal of its in vitro Behavior and tumor amelioration potential. Drug Deliv. 2016, 23, 2827-2837. [CrossRef] [PubMed]

37. Yingchoncharoen, P.; Kalinowski, D.S.; Richardson, D.R. Lipid-based drug delivery systems in cancer therapy: What is available and what is yet to come. Pharmacol. Rev. 2016, 68, 701-787. [CrossRef] [PubMed]

38. Torchilin, V.P. Recent advances with liposomes as pharmaceutical carriers. Nat. Rev. Drug Discov. 2005, 4, 145-160. [CrossRef] [PubMed]

39. Zoorob, G.; Burke, T. Enzymology and drugs. In DNA Topoisomerase Protocols; Osheroff, N., Bjornsti, M.A., Eds.; Humana Press: Totowa, NJ, USA, 2001; Volume II, pp. 215-227. ISBN 978-1-59259-057-5.

40. Kollmannsberger, C.; Mross, K.; Jakob, A.; Kanz, L.; Bokemeyer, C. Topotecan-A novel topoisomerase I inhibitor: Pharmacology and clinical experience. Oncology 1999, 56, 1-12. [CrossRef] [PubMed]

41. Dubertret, B.; Skourides, P.; Norris, D.J.; Noireaux, V.; Brivanlou, A.H.; Libchaber, A. In vivo imaging of quantum dots encapsulated in phospholipid micelles. Science 2002, 298, 1759-1762. [CrossRef] [PubMed]

42. Chinnathambi, S.; Abu, N.; Hanagata, N. Biocompatible CdSe/ZnS quantum dot micelles for long-term cell imaging without alteration to the native structure of the blood plasma protein human serum albumin. RSC Adv. 2017, 7, 2392-2402. [CrossRef]

43. Hao, Y.L.; Deng, Y.J.; Chen, Y.; Hao, A.J.; Zhang, Y.; Wang, K.Z. In Vitro cytotoxicity, in vivo biodistribution and anti-tumour effect of PEGylated liposomal topotecan. J. Pharm. Pharmacol. 2005, 57, 1279-1287. [CrossRef] [PubMed]

44. Tian, B.; Al-Jamal, K.T.; Kostarelos, K. Doxorubicin-loaded lipid-quantum dot hybrids: Surface topography and release properties. Int. J. Pharm. 2011, 416, 443-447. [CrossRef] [PubMed]

45. Sonali; Singh, R.P.; Singh, N.; Sharma, G.; Vijayakumar, M.R.; Koch, B.; Singh, S.; Singh, U.; Dash, D.; Pandey, B.L. Transferrin liposomes of docetaxel for brain-targeted cancer applications: Formulation and brain theranostics. Drug Deliv. 2016, 23, 1261-1271. [CrossRef] [PubMed]

46. Abraham, S.A.; Edwards, K.; Karlsson, G.; Hudon, N.; Mayer, L.D.; Bally, M.B. An evaluation of transmembrane ion gradient-mediated encapsulation of topotecan within liposomes. J. Control. Release 2004, 96, 449-461. [CrossRef] [PubMed] 
47. Yang, S.; Liu, C.; Liu, W.; Yu, H.; Zheng, H.; Zhou, W.; Hu, Y. Preparation and characterization of nanoliposomes entrapping medium-chain fatty acids and vitamin C by lyophilization. Int. J. Mol. Sci. 2013, 14, 19763-19773. [CrossRef] [PubMed]

48. Flowing Software, 1.47v; Software for Image Processing; National Institutes of Health: Bethesda, ML, USA, 1997. Available online: https:/ /imagej.nih.gov/ij/index.html (accessed on 27 June 2017).

49. Flowing Software, 2.5.1v; Software for Flow Cytometry Data Analysis; Turku Centre for Biotechnology: Turku, Finland, 2013. Available online: http://flowingsoftware.btk.fi/index.php?page=1 (accessed on 27 June 2017).

2017 by the authors. Licensee MDPI, Basel, Switzerland. This article is an open access article distributed under the terms and conditions of the Creative Commons Attribution (CC BY) license (http:// creativecommons.org/licenses/by/4.0/). 